\title{
Geografia dos domínios de Internet no Brasil*
}

\section{Marcelo Paiva da Motta}

Instituto Brasileiro de Geografia e Estatística (IBGE), Rio de Janeiro (RJ), Brasil

Resumo

O objetivo deste artigo é analisar a distribuição espacial da Internet na escala nacional, na dimensão da oferta de conteúdo. Para tanto, foi utilizado o registro de domínios como proxy da localização onde as informações são produzidas. Partiu-se da hipótese de que a espacialidade dos domínios, a despeito de sua imaterialidade, não prescinde de uma ancoragem espacial precisa, relacionando-se com processos materiais da sociedade. Isto é verificado pela comparação dos padrões espaciais dos domínios com a demografia e a distribuição das atividades econômicas em geral no território. Conclui-se que a geografia dos domínios é extremamente concentrada, contrariando o viés antigeográfico suscitado pela disseminação da Internet. Os resultados são consistentes com a abordagem institucionalista, pela qual as empresas que operam online tendem a se aglomerar nas metrópoles, integrando-se com o ambiente econômico prévio.

Palavras-Chave | Internet; Domínios; Geografia Econômica; Brasil.

Código JEL | R12.

* O autor agradece aos pareceristas anônimos por sua avaliação e contribuição para o aprimoramento da análise. 


\title{
Internet domain geography in Brazil
}

\begin{abstract}
The aim of this paper is to analyze the spatial pattern of internet on a national scale in the content offer dimension. We use domain name resgistration as a proxy of the location where the informations are produced. We start from the hypothesys that the domain spatiality is precisely attached to material processes of society. This is verified by comparing domain names spatial pattern with the distribution of demographics and economic activity in general. The conclusion is that the internet domain geography is highly concentrated despite the anti-geographic bias that emerged with internet diffusion. The results are consistent with the institutionalist approach, in which online operating firms tend to cluster mainly in metropolises, interweaving with the previous economic environment.
\end{abstract}

KEYWORDS | Internet; Domains; Economic Geography; Brazil.

JEL-CODE | R12.

\section{Introdução}

Este artigo trata da distribuição espacial da Internet em escala nacional, considerando a dimensão da oferta de informações, mais precisamente os nomes de domínio. Buscou-se apreender seus padrões comparando-os com o peso demográfico das cidades, a rede urbana preexistente e a geografia das atividades econômicas.

Os nomes de domínio são uma aproximação para determinar os lugares físicos onde o conteúdo na Internet é produzido e organizado. De acordo com Zook (2000), registrar um nome de domínio, mesmo sendo fácil e barato, representa uma decisão consciente de usar a Internet de maneira mais sofisticada, um esforço 
para organizar um corpo de informações e, potencialmente, disponibilizá-lo para o mundo. O registro de domínios tem seu papel reforçado mesmo com o advento de serviços que criam um arcabouço pronto para a geração de conteúdo por parte do usuário, como as redes sociais, que ganharam ímpeto a partir de meados dos anos 2000 e, juntamente com outras aplicações, formam a chamada web 2.0, uma evolução da organização de informações na rede, com ênfase na interação entre indivíduos e na geração de conteúdo pelo usuário individual. A facilidade de organização e publicação de informações que estes serviços propiciam faz com que não seja estritamente necessário o uso de um domínio próprio pelo usuário doméstico. O registro dos domínios passa a se concentrar, em grande medida, nas atividades comerciais, para as quais é importante como garantia de credibilidade na Internet, bem como para os que desejam maior personalização no formato de suas informaçōes.

Além disso, os domínios constituem a estrutura mais "solta" da Internet no que tange à infraestrutura física, refletindo mais diretamente os processos econômicos e sociais sem empecilhos do ponto de vista técnico. O administrador de um domínio tem liberdade para registrá-lo sob qualquer endereço de sua escolha, e nada o constrange a vincular o nome de domínio de sua responsabilidade a tal ou qual equipamento ou localização residencial ou comercial.

Embora não haja garantias de que o endereço registrado de um domínio coincida com o local exato de produção de seu conteúdo, a bibliografia vem mostrando uma correspondência significativa entre os dois, sobretudo no caso das empresas que usam a Internet para suas operações (ZOOK, 2000). O registro de um domínio, nesse caso, indica uma maior propensão ao uso e distribuição comercial de informaçóes, na esfera dos negócios, mais do que simplesmente a navegação por sites ou o uso pessoal de e-mail, que pertencem mais à esfera do consumo na Internet. Adicionalmente, em um mundo onde se intensifica o uso da informação como força produtiva direta, a propriedade intelectual da marca e de seu nome é um traço fundamental da produção de valor, sendo que a manutenção de um nome de domínio se impóe como uma necessidade do ponto de vista das empresas, que podem obter vantagens ao possuir um nome de domínio simples e de amplo conhecimento. Com o avanço cada vez mais intenso da Internet e das oportunidades de negócios que ela cria, passa a existir um mercado de nomes de domínio, no qual aqueles que podem conferir alta visibilidade a seu mantenedor são alvos de disputas severas entre as empresas - vide o caso dos domínios Pizza. 
com e Vodka.com, vendidos, respectivamente, por 2,6 milhóes de dólares em 2008 e 3 milhões de dólares em 2006. ${ }^{1}$

No presente estudo, parte-se da hipótese de que a lógica espacial de distribuição dos domínios não prescinde de uma ancoragem espacial precisa, apesar de seu caráter fortemente imaterial. Sendo uma delimitação do direito de controle de boa parte do que é ofertado como conteúdo na Internet, os domínios estão relacionados com processos materiais da sociedade, desde a mera localização das pessoas com habilidades de criá-los até a capacidade de algumas localidades de gerarem ambientes propícios aos negócios online, passando pelo tamanho e pelos padrôes das economias locais. Daí é necessário comparar sua repartição no espaço com padrões preexistentes, como a demografia e a geografia das atividades econômicas, assim como verificar de que forma se dá sua difusão.

Acrescenta-se aqui uma ressalva. É comum a identificação do presente tema com a categoria "ciberespaço", ou então com uma "geografia do virtual", noções que, entretanto, são rejeitadas neste trabalho. O ciberespaço é uma metáfora, pela qual a rede de nós e ligaçôes formada pelos computadores online pode ser considerada funcionalmente equivalente ao espaço (ADAMS, 1997), reproduzindo ao menos algumas de suas propriedades (posição, movimento, direção), mas estruturado pelas interações e não pela proximidade. Nesse sentido, via de regra, são ressaltadas suas características de virtualidade e de ser um espaço etéreo, simultaneamente infinito e ubíquo, em que todos os participantes são tidos como presentes em um mesmo local (GRAHAM, 2011), embora desincorporados, requerendo mesmo uma "transcendência do corpo" para aí atuarem (ADAMS, 1997, p. 164).

O presente artigo não trata da criação de uma nova ontologia espacial criada pela interatividade remota (BATTY, 1997), nem é o estudo da interação entre espaços "reais" e "virtuais" (TAKEYAMA, 2001). A metáfora de ciberespaço introduz uma dualidade entre real e virtual - como Takeyama admite nas entrelinhas -, criando um mundo exotérico, externo ao cotidiano, que cada vez menos serve para descrever a realidade da interação que tem a Internet por meio. Tendo em vista que o formato digital desempenha papel cada vez mais banal em nossas vidas, borrando as fronteiras entre o que poderia ser considerado uma interação do "mundo virtual" e do real (pense-se na Primavera Árabe, por exemplo, toda arquitetada por redes sociais online), a atenção aqui volta-se para o espaço concreto, de como seus atributos influenciam a localização de um processo imaterial - a criação de conteúdo para a internet.

1 BBC News, 04/04/2008. Disponível em: <http://news.bbc.co.uk/go/pr/fr/-/2/hi/americas/7331042.stm> 


\section{Uma estrutura imaterial: o que esperar}

O crescente número de pessoas que fazem uso da Internet, no Brasil, leva à comparação dos domínios com os padrōes demográficos do território, como se verá nas subseçōes seguintes. O próprio aumento do uso dessa rede, fazendo surgir desde práticas inusitadas até a sua consolidação como meio de realização de transações comerciais, mostra que é necessário ir mais além, pois abarca processos mais complexos. À medida que a Internet vai se tornando uma feição comum do dia-a-dia, mais as atividades econômicas fazem uso dela como meio de produção de valor, ou para realizar transaçōes em alguma etapa importante de suas cadeias produtivas. Isto é realizado pelo comércio eletrônico direto, isto é, a venda a varejo para o consumidor final (B2C ou Business-to-consumer), pelas relações de trocas entre empresas (B2B ou Business-to-business), por diversos serviços especializados de intermediação de leilóes e trocas online ( $\mathrm{C} 2 \mathrm{C}$ ou Consumer-to-consumer), pela criação de redes privadas na Internet entre empresas de fornecedores e clientes, pela realização de licitações e compras pelos governos por meios eletrônicos, pela prestação de serviços dos governos e cobrança de impostos aos cidadãos, assim como pela simples publicação de informações referentes à atuação de mercado das empresas que têm em seus sites mais uma maneira de divulgação de seus produtos e serviços. Dessa forma, mais do que a mera comparação com o peso demográfico, este estudo busca identificar a relação entre a distribuição espacial dos domínios e a das atividades econômicas, como vistas pelo número de empresas formais nas cidades.

Embora nem todo domínio seja de uso comercial, essa dimensão está fortemente presente em toda a Internet. Mesmo em páginas e conteúdos não voltadas para o lucro, é comum a utilização de anúncios publicitários, parcerias com empresas de e-negócios e outras formas de levantamento de fundos, o que torna razoável a comparação da distribuição espacial dos nomes de domínios com as atividades econômicas convencionais. Além disso, deve ser levado em conta o contexto atual de crescente digitalização dos bens informacionais, envolvendo os produtos dos setores de entretenimento, da informação e financeiro, bem como os mais diversos serviços imateriais, que têm na Internet um canal preferencial de distribuição.

Nesse contexto, as empresas surgidas para operar na Internet, a partir de meados dos anos 1990, foram logo consideradas um modelo de negócios disruptivo, pois pensava-se que iriam contornar os canais habituais de distribuição, relacionar-se diretamente com clientes sem intermediários, cortando os custos tradicionais com a instalação de lojas físicas - o que a literatura define como "desintermediação" 
(WRIGLEY; CURRAH, 2006). De fato, alguns exemplos bem-sucedidos pareciam confirmar essa tendência, como as empresas Amazon.com, de crescimento meteórico, a loja eletrônica do setor de brinquedos eToys e o serviço de leilōes eBay nos EUA. No caso brasileiro, o exemplo mais citado é o do bem-sucedido e-tailer Submarino. Porém, a continuidade deste modelo, que se refletiu no avanço da bolha especulativa "ponto com" até 2000, não se efetivou plenamente. Grande parte das companhias que operavam na Internet tinha modelos de negócios pouco factíveis, mais baseados em expectativas irracionais geradas pela nova tecnologia da Internet e pelo modismo do que em um planejamento bem elaborado de execução de operaçōes. Financiadas por capitais ávidos por valorização e crescimento rápidos e novas oportunidades, o setor de negócios que operava na Internet ganhou uma enorme dimensão especulativa em fins dos anos 1990, potencializado por um processo de retroalimentação positiva: quanto mais "empresas ponto com" recebiam investimento, mais diferentes setores do capital queriam inserir-se nesse processo de valorização, aumentando o montante das inversões (ZOOK, 2005). O processo acabou se mostrando insustentável quando houve o estouro da "bolha ponto com" em 2000, com o índice Nasdaq atingindo o ápice em março daquele ano e desabando em seguida. A questão é que essas injeçōes de capital tinham por objeto empresas de pouca base, fracamente rentáveis de fato e mesmo com falhas organizacionais fundamentais, como demonstrado por Thornton e Marche (2003).

O resultado foi um reajuste doloroso do mercado, no qual só permaneceram as empresas com planos de negócios mais robustos. À medida que as firmas tradicionais, baseadas em instalações físicas, reagiram à concorrência e começaram elas mesmas a operar na Internet, o processo de eliminação das novas companhias online de fraco desempenho foi acelerado exatamente porque aquelas já possuíam uma estrutura logística e organizacional bem fundamentada.

As transações comerciais envolvem uma ancoragem espacial pela qual as empresas devem adequar-se a características, restriçōes, hábitos de consumo e normas dos mercados em que operam, em diferentes escalas. Embora isto seja mais evidente no caso das mercadorias tangíveis, também é valido no dos bens informacionais. Por exemplo, a loja Amazon.com citada anteriormente não vende música em formato mp3 por download - a rigor um método que contorna restrições espaciais - para compradores fora do território americano, de maneira a evitar problemas legais com os detentores de direitos autorais que se baseiam nas leis daquele país. Apesar de acessíveis de qualquer conexão à Internet, não importando de onde, os sites das empresas de comércio eletrônico acabam por ser moldados na prática para servir o 
tipo de mercado onde as próprias companhias estão inseridas, seguindo não só as regras locais, mas também refletindo os interesses e características de seus clientes - processo extremamente facilitado pela interface web, podendo chegar mesmo ao nível da personalização (WRIGLEY; CURRAH, 2006).

O fato de haver uma "geografia escondida" por trás das operaçōes comerciais via Internet, com capital fixo, infraestrutura de transporte, comunicaçōes e armazenagem materializada no espaço, é mais um fator espacialmente limitante para as empresas de comércio eletrônico. O custo dessa complicada logística se mostrou como critério de eliminação para diversas firmas, sobretudo no varejo, que é o setor de maior visibilidade. Nesse sentido, são exatamente as maiores corporações que já possuem competências desenvolvidas em suas áreas de atuação, como repor estoques, distribuição para estabelecimentos dispersos no espaço e lidar com múltiplos pedidos simultaneamente, que melhor se adaptaram às operações pela Internet, tornando-se empresas multicanal (operam tanto online como no "mundo real") (CURRAH, 2002). Ao mesmo tempo, as empresas "puras" de Internet que mais prosperaram foram aquelas que optaram por fixar capital em suas cadeias logísticas, como em grandes armazéns.

Por esse motivo é que Lasserre (2000) vê a logística como atividade espacialmente incontornável, cuja demanda cresce com o advento do comércio eletrônico. A necessidade física de entrega de produtos suscitada pelas transaçōes à distância e a pressão concorrencial pela aplicação de prazos curtos fazem com que ela se torne um setor essencial das empresas, que tentam dominar o espaço de maneira a fazer circular os produtos e serviços de um ponto a outro. Um sintoma dessa importância aumentada da logística é o florescimento de empresas transportadoras habilitadas a operar em escala global, como FedEx, UPS e TNT. As cidades que possuem pontos de apoio logísticos desempenham, portanto, um papel limitador no tocante à localização de empresas que usam a Internet como canal de distribuição.

Uma vez que seu trabalho nos bastidores, isto é, aquele que sustenta suas operações online, é específico do lugar e totalmente integrado com o ambiente econômico offline, é mais fácil inserir-se onde as estruturas dessa geografia já estão construídas, bem como nos locais com alta densidade das redes de relacionamentos, não raro cara a cara, entre profissionais, empresários, fornecedores e clientes.

A questão da imbricação do comércio eletrônico com o ambiente econômico onde ele se localiza, largamente ausente no imaginário de ubiquidade suscitado pela popularização da Internet enquanto mídia de mainstream, leva a crer que a abordagem institucionalista (AMIN, 2002; STORPER, 1997) pode também jogar luz sobre a presença deste tipo de firma. 
As empresas baseadas em comportamentos inovativos necessitam ter acesso a recursos relevantes em termos de informação, conhecimento, tecnologia, novas ideias, treinamento de funcionários, estar a par das flutuaçóes de mercado e outras feiçôes importantes para a sua atuação. Esse tipo de recurso está pautado pelo know-how diário do processo de trabalho, que não necessariamente é codificável, isto é, transmissível por símbolos, textos, gráficos, etc., mas criado tacitamente na interação cotidiana entre os agentes. Além do know-how, possuir uma rede social de contatos-chave para a realização dos negócios também desempenha papel relevante.

Criam-se, então, interdependências imateriais entre as companhias. Combinando competição e cooperação, as trocas de conhecimento e informações entre elas geram economias externas que as mantêm unidas à região onde se localizam. As instituições presentes nas regiōes onde as empresas se aglomeram, entendidas como o conjunto de regras e rotinas que permeiam o funcionamento das firmas, sua cultura corporativa, os contatos profissionais entre elas e o saber tácito lá construído, formam um ambiente que ajuda (ou prejudica) a realização de inovações.

Enquanto a Internet permite que uma grande quantidade de informações codificáveis possa se globalizar facilmente, este tipo conhecimento tácito especializado permanece atrelado ao lugar, sendo quase que exclusivamente transmitido com base na proximidade espacial, nas transações entre empresas. As trocas de informação não codificável necessitam de uma base relacional na qual a confiança entre as partes possa se estabelecer. Isto não necessariamente pode ser formalizado por meio de contratos, mas sim por um histórico de transações entre os agentes econômicos, raramente conseguido só por contatos via Internet ou outro método de telecomunicação. A isso adiciona-se o fato de que as tecnologias tradicionais de transporte, terrestre e aéreo, sofrendo com congestionamentos e saturação de infraestrutura, podem aumentar consideravelmente o custo de contatos face a face caso seus atores estejam distantes uns dos outros (LEAMER; STORPER, 2001).

A dificuldade em gerar e transmitir conhecimento e informações sobre os negócios que gravitam em torno da Internet funciona como uma força centrípeta, atraindo as empresas a se situarem próximas umas das outras.

Quanto maior e mais intensa for a frequência das interações interempresariais, mais a proximidade física será necessária em virtude de sua informalidade. Mesmo que não houvesse transações entre firmas, sua concentração ainda seria necessária apenas por causa da possibilidade de monitoramento mútuo de seu comportamento, de modo fácil e com um baixo custo, propiciando a imitação dos casos de sucesso e a aprendizagem com os erros (MASKELL, 2001). 
Esses aportes teóricos aqui utilizados apontam na direção de um comportamento urbano e concentrado para a produção do conteúdo na Internet, bem como de seu uso como plataforma para realização de negócios. Com efeito, tomando como pressuposto que os nomes de domínios constituem um componente e uma manifestação essencial do espaço de fluxos que caracteriza a sociedade atual (CASTELLS, 1999), este estudo busca identificar a relação entre sua presença no espaço e os pontos de apoio concreto que viabilizam as trocas de informação, a transmissão de decisões e os fluxos de capital, nomeadamente as grandes cidades.

Porém, Townsend (2001) apresenta uma visão diferente, criticando a hipótese das cidades globais de Sassen e indo na contramão da visão econômica institucionalista. Segundo o autor, a emergência da Internet a partir dos anos $1990 \mathrm{fez}$ surgir um grupo de regióes produtoras de informação maior e mais descentralizado do que se previu nos EUA. De acordo com seu estudo, que usa como base as ligações de fibras óticas entre cidades e os próprios domínios, isto representa um padrão espacial inteiramente novo, mais sensível à descentralização, já que os produtos de mais alto valor - informação e conhecimento - são razoavelmente indiferentes à distância. Assim, a Internet representa uma oportunidade de remodelar as relaçôes entre as cidades: "no lugar de um punhado de regióes dominando a cultura e as finanças globais, uma constelação de regiōes altamente especializadas hoje interage em uma economia globalmente telemediada" (TOWNSEND, 2001, p. 43, tradução nossa).

Neste estudo, serão comparadas a presença de domínios e a distribuição das atividades econômicas como forma de tentar enquadrar o caso brasileiro em uma dessas visões antagônicas e medir o quanto a oferta de um novo serviço de comunicações e de conteúdo à distância tem o poder de rearranjar as relações já estabelecidas entre os centros urbanos.

Outro elemento que auxilia a esclarecer o papel dos domínios é a sua difusão espaço-temporal, verificando quais localidades passam a adotá-los e se há conexão com os polos de maior atividade de Internet. Segundo a teoria da difusão de inovações, as novas tecnologias não surgem simultaneamente em todo o espaço. Algumas pessoas e lugares têm acesso imediato, outros o ganham de maneira tardia, enquanto alguns nunca o têm (BROWN, 1981, p. 1). Hägerstrand (1967), pioneiro em formalizar a teoria da difusão de inovaçōes na geografia, considera a adoção de uma inovação um processo de aprendizagem que condiciona os padróes de comportamento: os adotantes tomam conhecimento de novas tecnologias, e quanto mais estas são adotadas por mais indivíduos, as resistências à mudança vão sendo vencidas. A famosa curva de crescimento em "s" é estabelecida - inicialmente a adoção é fraca, ganha- 
se ímpeto crescendo fortemente a partir de determinado momento e, nos estágios finais, tende-se à saturação. A contiguidade desempenha papel importante, já que os locais próximos aos do surgimento da inovação a adotam primeiro que os mais distantes, padrão que pode também ser condicionado pela presença de infraestrutura.

A abordagem clássica da difusão de inovações tem sido caracterizada pela literatura como a "perspectiva da adoção" (BROWN, 1981) ou "enfoque da informação" (OLIVEIRA et al., 1978), focada no surgimento de tecnologias voltadas para o consumidor, na exposição dos indivíduos ao processo inovativo e na comunicação individual como forma de disseminação de informações sobre a inovação. Outra abordagem desenvolvida por Brown é a perspectiva de "mercado e infraestrutura", que enfatiza o lado da oferta da inovação, com base na atuação governamental e de entidades privadas criando agências de promoção da inovação que formam um quadro de escolhas para o indivíduo. A estrutura dos dados sobre os domínios, como será visto, parece ser mais consistente como sendo uma inovação referente às empresas. Porém, o enfoque de mercado e infraestrutura não se mostra plenamente adequado.

A inovação tecnológica para uso empresarial, nos processos produtivos e transações comerciais, possui algumas particularidades em relação ao enfoque da informação. É necessário levar em conta a natureza da inovação em si, pois o investimento na mudança da tecnologia empregada ou o uso de uma nova ferramenta deve ser mais rentável do que a antiga. Isto remete a outro tipo de questão, como o tamanho das empresas e a disponibilidade de capitais.

Contudo, optou-se pela abordagem clássica por ser pertinente no presente caso, pois, além de a difusão de inovaçóes pelas empresas ser compatível com a perspectiva da adoção, conforme indicado por vários estudos (BROWN, 1981, p. 152), o objeto deste estudo constitui um nova tecnologia de uso geral, externa à imensa maioria dos ramos de negócios existentes. Dessa forma, as empresas tomadas isoladamente tornam-se análogas a um consumidor individual, adotando tal ou qual inovação. Além disso, os conteúdos disponíveis na Internet e a forma que ela assume estão, até o momento presente (2011), largamente desregulamentados, sendo sua disseminação feita à moda do livre mercado, em que o efeito demonstração tem papel relevante, sem "agências de disseminação" centralizadas - tal como a teoria clássica trata. $\mathrm{O}$ "efeito de clube", o "boca a boca" e a exposição individual à informação sobre a inovação, dessa maneira, parecem constituir sua forma principal de disseminação.

À luz desses aportes teóricos, verificar-se-á como se comporta espacialmente a produção de conteúdo online no Brasil. Para tanto, cabe primeiramente alguns esclarecimentos acerca da natureza do dado em que esse trabalho é baseado: os nomes de domínio de Internet. 


\section{Sobre os nomes de domínio}

A Internet conheceu um crescimento vertiginoso na quantidade de conteúdo online a partir da invenção da world wide web (ou simplesmente www) por Berners-Lee em 1991, mesmo antes de sua abertura comercial ao público. Frequentemente confundida com a própria Internet, a web constitui uma aplicação para esta rede que liga documentos de texto, imagens, som e vídeo entre si, por meio de uma interface mais amigável para o usuário leigo. Os nomes de domínios são aí uma feição central para a localização de informações (NAUGHTON, 2000).

O sistema de nomes de domínio (DNS, Domain Name System), criado em realidade antes da web nos anos 1980, habilitou a proliferação dos sites com protocolo HTTP, rapidamente difundidos sob a forma "http://www.nomededominio.n". $\mathrm{Na}$ medida em que a Internet foi aberta para o público em geral, surgiram enormes oportunidades de mercado, alavancando a disseminação do domínio genérico ".com”, inicialmente voltado apenas para entidades comerciais. O número esmagador de registros deste tipo de domínio fez com que o "ponto com" se tornasse um padrão geral de facto da Internet a partir de meados dos anos 1990 (ABBATE, 2000).

Uma das maneiras mais importantes de ofertar conteúdo na Internet é pela manutenção de um domínio. Em que pesem, de um lado, a persistência de formas mais antigas de lidar com o conteúdo online, como o e-mail (ainda hoje altamente popular) e os grupos de notícias, e, de outro, o surgimento de inovaçoes, como as redes de troca P2P, com as mais diversas aplicações (voz sobre IP, redes sociais, fluxos de vídeo) e uso de dispositivos móveis como celulares e Tablets (ANDERSON; WOLFF, 2010), os domínios retêm sua importância ao definir uma zona na qual um indivíduo ou organização mantém autoridade sobre determinado conteúdo. Apesar de várias dessas formas de comunicação pela Internet passarem ao largo da hierarquia de nomes de domínio, evidente no caso da troca de arquivos, em algum momento elas têm na web uma faceta importante para seu funcionamento, na qual a manutenção de um domínio é condição estritamente necessária.

O domínio de Internet é um nome que identifica um ou mais computadores na rede mundial, associados a um conteúdo específico. Cada domínio é único, constituído de uma combinação de números e/ou letras que é registrada de modo centralizado e hierárquico, à maneira de uma lista telefônica. Todo domínio precisa necessariamente estar cadastrado neste sistema, uma vez que sua função é traduzir seu nome alfabético ou alfanumérico para o endereço $\mathrm{IP}^{2}$ correspondente e, dessa forma, apontar o computador de cada usuário para a direção correta.

2 O IP (Internet Protocol) é um número que identifica cada computador na Internet. 
O sistema de endereçamento na Internet possui uma estrutura hierárquica arborescente. Inicia-se, em seu nível mais elevado, na zona de raiz, que não possui nome formal e tem a função de delegar a operação dos domínios de topo, ou primeiro nível. Atualmente encontra-se administrado pelo ICANN (Internet Corporation for Assigned Names and Numbers), entidade sem fins lucrativos localizada nos Estados Unidos.

Os domínios de topo, por sua vez, se dividem em dois: os domínios de primeiro nível genéricos (gTLD - Generic Top Level Domains), como, por exemplo, os ".com”, “.org”, “.net”, que podem localizar-se em qualquer lugar do planeta; e os domínios vinculados geograficamente a um Estado (ccTLD - Country Code Top Level Domains), tais como ".br" no caso brasileiro, ".uk” para o Reino Unido, ".fr" para a França e assim sucessivamente. ${ }^{3}$

Cabe enfatizar que, embora represente uma descentralização relativa à forma de endereçamento das redes de computadores anterior a meados dos anos 1980, o sistema de nomes de domínio permanece com um grau de centralização bem alto. Geralmente, cada Estado Nacional possui uma entidade que normatiza e coordena a atribuição de nomes de domínio, bem como a lista de correspondência entre eles e os endereços IP, a qual se encontra armazenada em um punhado de computadores, denominados servidores DNS de raiz. Além desses, há uma série de outros servidores DNS secundários, que funcionam em redundância com a raiz, além de armazenar endereços locais e acelerar o processo de busca oriunda de áreas que lhes são geograficamente próximas. Todo esse sistema é periodicamente atualizado e sincronizado, já que discrepâncias podem causar caos no funcionamento da rede.

No Brasil, a instituição responsável pelo registro dos domínios “.br" é o Comitê Gestor da Internet (cig.br), por meio de sua entidade executora Registro.br, que cataloga, normatiza e julga os pedidos de registro de novos domínios em todo o território nacional. Qualquer pessoa ou entidade pode requerer um domínio ".br", para o que são exigidos um CPF ou CNPJ e um endereço de contato no país. Dessa maneira, todo domínio terá uma ficha de registro com o nome de seu responsável, incluindo seu endereço físico. Cabe salientar que somente a partir de $1^{\circ} \mathrm{de}$ maio de 2008 o Cgi.br passou a admitir que os domínios “.com” passassem a ser registrados com CPF. Anteriormente a essa data era exigido, necessariamente, um CNPJ. ${ }^{4}$

Os dados utilizados no presente trabalho foram cedidos pelo Registro.br e constituem uma agregação do número de domínios por CEP. Como não há bases

3 Para um maior detalhamento da arquitetura do sistema de nomes, ver Carvalho et al. (2004).

4 Disponível em: <http://www.registro.br/anuncios/20080416.html> 
cartográficas utilizando o endereçamento postal dos Correios, os dados foram posteriormente agregados por município. O conjunto dos dados é composto de duas séries com a totalidade dos domínios terminados em “.br” em março de 2005 e março de 2006. A série de 2005 perfaz 741.682 domínios e a de 2006 contém 887.006 domínios - um crescimento de praticamente $20 \%$ em um ano. As informações são de natureza declaratória por parte dos mantenedores de cada domínio.

Em virtude da semelhança na distribuição espacial das duas séries, optou-se, para a realização do diagnóstico da situação da produção de informações online, por analisar a série mais recente, a de 2006.

Esses dados têm limitações, já que imprecisões e erros estão presentes. Dos domínios de 2006, 10.135 (1,14\% do total) estão classificados pelo próprio Registro. br como erro, isto é, não correspondendo a um CEP existente. Além disso, uma desvantagem inerente ao uso deste tipo de dado é a homogeneização das entidades que administram os domínios, pois tanto um site de uma grande corporação multilocalizada quanto o de uma pequena empresa ou mesmo uma página pessoal são tratados como iguais, sem contar com a já mencionada questão de não haver plena segurança de que o local do registro seja o mesmo da produção do conteúdo.

Esses pontos negativos, entretanto, não desautorizam a análise, pois não há motivos para crer que eles tenham algum viés espacial inerente, ${ }^{5}$ exceto o caso das empresas multilocalizadas, que tendem a registrar seus domínios com o endereço das sedes, o que contribui para uma ligeira sobrerrepresentação dos grandes centros urbanos. De qualquer maneira, o montante de erros é baixo e um eventual erro de preenchimento do CEP por parte do declarante que não tenha sido classificado como tal pelo Registro.br acabou sendo diluído quando os dados foram agregados por município. Em relação à diferença de tamanho dos controladores de domínios, este problema é naturalmente minimizado, uma vez que há a tendência de as empresas, sobretudo as de maior porte, registrarem vários domínios correspondendo ao mesmo conteúdo, o que aumenta sua representação na base de dados.

A base de nomes de domínio aqui utilizada diz respeito apenas aos ccTLD do Brasil, isto é, os terminados em ".br". Estão excluídos, por não serem da alçada do Registro.br, os domínios gTLD (“.com”, “.net”, etc.), cujo conteúdo pode ser

5 Uma possível fonte de distorção é a prática do chamado cybersquatting, pela qual um fraudador registra antecipadamente domínios com nomes de empresas, marcas famosas e/ou com grafia semelhante, com o intuito de redirecionar visitantes para outros sites ou mesmo chantagear companhias para a compra de domínios com seu nome. Para tanto, o cybersquatter tem diversos registros sob o mesmo endereço. Porém, o próprio Registro.br busca coibir essa prática, cancelando o contrato para a requisição de domínios em casos em que o nome "induza terceiros a erro, [e] que viole o direito de terceiros" (https://registro.br/dominio/contrato.html). 
produzido no país ou não, sendo que seu registro fica a cargo de diversas entidades privadas de registro autorizadas pelo ICANN. No Brasil há sete companhias de registro genérico (set./2010), ${ }^{6}$ porém nada impede um registrante no país de usar o serviço de uma empresa semelhante situada no estrangeiro. A opção pelos ccTLD acaba negligenciando uma parte significativa da oferta de conteúdo online realizada no país, em função do caráter relativamente fluido dos fluxos de informação na Internet, que contorna parcialmente as fronteiras nacionais. Entretanto, tudo indica que, para os objetivos do presente trabalho, centrados na escala nacional, os domínios ".br" representam uma amostra significativa. Segundo o estudo de Zook (2001), os domínios ccTLD são, geralmente, caracterizados fortemente pela produção endógena, nas línguas nacionais, enquanto os domínios genéricos TLD são mais voltados para o público global, com conteúdo normalmente em inglês. Além disso, em uma tipologia baseada na quantidade de domínios e no número de usuários, este autor classifica o Brasil como um país que, simultaneamente, apresenta um sistema de desenvolvimento de conteúdo interno bem desenvolvido e também é um "exportador" na Internet (isto é, possui conteúdo significativamente voltado para o público internacional). Mesmo possuindo um grande número de domínios gTLD, o Brasil situava-se, em 2010, em oitavo lugar no ranking de operadores de domínios ccTLD no mundo, sendo um dos três países entre os 25 maiores em ccTLD que alcançaram taxas de crescimento acima de $25 \%$ no registro de novos domínios (25,9\% em relação a 2009) (VERISIGN, 2010).

\section{Os domínios no espaço}

A oferta de informações na Internet em território nacional, via presença de domínios, é encontrada na maioria dos municípios brasileiros. Utilizando as Áreas de Concentração da População (ACPs) para agregar os municípios que fazem parte de uma mesma mancha urbana (como nas áreas metropolitanas, por exemplo) (CASTELLO BRANCO, 2006) e, quando não aplicável, os municípios, é possível verificar que, das 5.274 unidades espaciais, ${ }^{7} 3.367$ possuíam pelo menos um domínio em março de 2006 (63,8\%). Isto não significa, porém, que a prática de registrar e administrar um domínio esteja disseminada. Sua estrutura é muito concentrada. Entre as cidades que os detêm, a distribuição é enormemente desigual, sendo que

6 Disponível em: <http://www.verisign.com/domain-name-services/find-registrar/index.html>

75.518 municípios instalados em 2005 mais 46 áreas de concentração de população. Doravante o termo "cidade" será usado significando o conjunto das ACPs e municípios. 
metade possui seis ou menos domínios. Por outro lado, a área metropolitana de São Paulo detém, sozinha, 287.780 domínios (32,7\% do total). A Tabela 1 apresenta as cidades com o maior número de domínios.

TABELA 1

Cidades com mais de 0,5\% dos domínios de Internet Brasil - 2006

\begin{tabular}{|c|c|c|c|}
\hline UF & Cidades & Domínios & $\%$ \\
\hline $\mathrm{SP}$ & São Paulo & 287.780 & 32,71 \\
\hline RJ & Rio de Janeiro & 87.229 & 9,92 \\
\hline PR & Curitiba & 39.038 & 4,44 \\
\hline MG & Belo Horizonte & 34.110 & 3,88 \\
\hline RS & Porto Alegre & 32.715 & 3,72 \\
\hline $\mathrm{SP}$ & Campinas & 24.985 & 2,84 \\
\hline DF & Brasília & 17.441 & 1,98 \\
\hline BA & Salvador & 15.141 & 1,72 \\
\hline SC & Florianópolis & 12.831 & 1,46 \\
\hline $\mathrm{PE}$ & Recife & 11.116 & 1,26 \\
\hline CE & Fortaleza & 10.329 & 1,17 \\
\hline $\mathrm{GO}$ & Goiânia & 10.238 & 1,16 \\
\hline $\mathrm{SP}$ & Santos & 9.580 & 1,09 \\
\hline ES & Vitória & 9.555 & 1,09 \\
\hline $\mathrm{RS}$ & Pelotas & 8.514 & 0,97 \\
\hline SP & São José dos Campos & 8.371 & 0,95 \\
\hline $\mathrm{PA}$ & Belém & 7.692 & 0,87 \\
\hline $\mathrm{SP}$ & Ribeirão Preto & 7.369 & 0,84 \\
\hline $\mathrm{SP}$ & Sorocaba & 7.256 & 0,82 \\
\hline SC & Joinville & 5.522 & 0,63 \\
\hline $\mathrm{RS}$ & Novo Hamburgo & 5.482 & 0,62 \\
\hline $\mathrm{SP}$ & Jundiaí & 5.234 & 0,59 \\
\hline MS & Campo Grande & 5.209 & 0,59 \\
\hline $\mathrm{PR}$ & Londrina & 4.961 & 0,56 \\
\hline $\mathrm{SP}$ & São José do Rio Preto & 4.792 & 0,54 \\
\hline RS & Caxias do Sul & 4.633 & 0,53 \\
\hline$P R$ & Maringá & 4.420 & 0,50 \\
\hline
\end{tabular}

Fonte: Registro.br 2006. 
Nota-se a preponderância de cidades do Sudeste e do Sul, particularmente do Estado de São Paulo, cuja capital encontra-se em um patamar muito superior. A megalópole São Paulo - Campinas - Santos também está presente entre os maiores detentores de domínios, bem como várias outras cidades do interior desse Estado. A única presença da Região Norte é Belém, localizada em um mesmo patamar de cidades médias como Ribeirão Preto e Sorocaba.

Considerando a forma geral da distribuição espacial dos domínios no território, chama atenção seu caráter restrito. Eles estão localizados em "ilhas" - municípios mais ou menos isolados -, com o espaço entre eles tendo fraca representatividade, concentrados, sobretudo, no Centro-sul, nas capitais estaduais e maiores cidades em geral, o que já é indício do caráter fortemente urbano da Internet, principalmente neste quesito da oferta de conteúdo. Com efeito, a aplicação do coeficiente de autocorrelação espacial de Moran, apresentando valor muito próximo a zero, indica que a contiguidade desempenha quase nenhum papel, ou, em outras palavras, o surgimento de domínios em certo local se dá de maneira independente do que se passa com seus vizinhos ${ }^{8}$ (Cartograma 1). Isto é sobretudo verdadeiro quanto maior a ordem de vizinhança das unidades espaciais (sendo a primeira ordem os vizinhos imediatos) - com uma pequena variação para mais no índice na ordem 4 muito pouco significativa.

Já os 1.907 municípios que não possuem domínios (36,2\% do total.) espalhamse por todo o país, com maior expressão no Norte e no Nordeste, sobretudo em Roraima (86,7\% dos municípios sem domínios), Piauí (82,8\%), Amapá (71,4\%) e Paraíba $(68,1 \%)$. Há, entretanto, presença significativa de municípios sem domínios em contiguidade com as áreas onde eles existem em maior densidade, o que é condizente com seu comportamento insular. Esta aparente falta de padrão é corroborada pelo valor do índice de autocorrelação espacial ser próximo a zero.

Os Estados na situação oposta, com poucos municípios sem domínios, são Rio de Janeiro, com apenas um município (Varre-sai), Espírito Santo (5,6\% do total de cidades do Estado) e São Paulo (10,4\%). Isto não quer dizer, entretanto, que a situação fora das capitais ou áreas metropolitanas seja tão expressiva, uma vez que a estrutura concentrada da oferta de conteúdo na Internet faz com que a maior parte das cidades tenha um número muito baixo de domínios. Por exemplo, em termos de presença de domínios, a maior cidade não metropolitana no Rio de Janeiro é

8 Quando o coeficiente de Moran (M) é próximo a zero não há autocorrelação espacial. Se $M>0$ a correlação é positiva e os lugares próximos tendem a ser semelhantes. Se $\mathrm{M}<0$ a correlação é negativa e os locais próximos tendem a ser mais dessemelhantes que os distantes (PUMAIN; SAINT-JULIEN, 1997). 
a ACP de Volta Redonda com pouco mais de 1.467 domínios, o que é 59,5 vezes menor do que a área metropolitana da capital. Já em São Paulo a situação não é tão diferente. A metrópole paulistana é 11,5 vezes maior em termos de domínios do que o a metrópole de Campinas e 34 vezes maior do que a cidade não metropolitana com maior número de domínios do Estado (São José dos Campos, com 86.371 domínios).

O mapeamento da distribuição absoluta dos domínios deixa transparecer que, apesar do imaginário de ubiquidade que a Internet propicia e da suposta morte das distâncias, seu funcionamento apresenta desigualdades espaciais marcantes no que toca à oferta de conteúdo. Isto indica que, do ponto de vista da geração de informações, a localização é muito importante, e alguns pontos no território parecem estar mais habilitados a produzir material online do que outros.

\section{CARTOGRAMA 1}

Distribuição dos domínios de Internet 2006

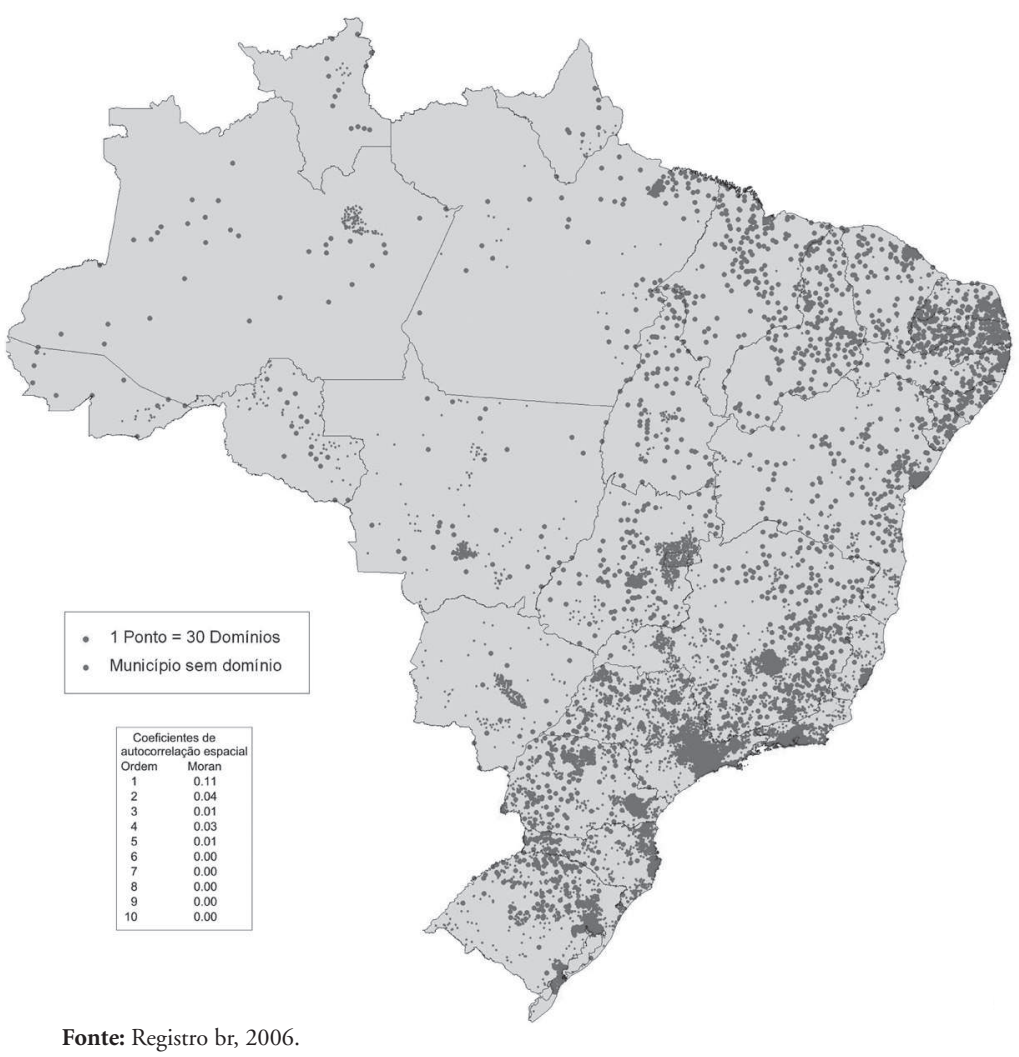


A presença dos domínios em termos absolutos espelha, grosso modo, o peso demográfico: têm mais probabilidade de possuí-los as cidades de maior população. Como o tamanho mascara a penetração da Internet nas localidades menores, buscou-se, assim, calibrar esta cifra por número de habitantes, o que faz emergir padrōes diferentes do simples mapeamento absoluto, fato também observado para os domínios na escala na União Europeia (ZOOK, 2001), nos Estados Unidos (ZOOK, 2005), na França (DUFÉAL, 2004) e na Alemanha (STERNBERG; KRYMALOWSKI, 2002).

A relativização da distribuição dos domínios (no de domínios em 2006/população do município em $2007^{*}$ 100) pode ser visualizada no Cartograma 2 e faz despontar a região metropolitana de São Paulo e algumas cidades em seu entorno, estando a própria metrópole em $16^{\circ}$ lugar. Na primeira posição surge Fernando de Noronha (com 3 domínios por 100 habitantes), seguido por São Sebastião-SP (2,56 por 100 hab.) e Alfenas-MG $(2,16)$. Vale observar a presença de diversas cidades de caráter marcadamente turístico e/ou balneários entre aquelas com maior número de domínios por habitantes, como Fernando de Noronha e São Sebastião (SP), Capão da Canoa (RS), Holambra (SP), Armação dos Búzios (RJ), Gramado (RS), Balneário Camboriú (SC), entre outras. A alta correlação da presença de domínios com o setor de turismo deve-se à importante relevância econômica local deste ramo de negócios, fazendo com que o número de sites oferecendo hospedagem, pacotes de viagem, passeios, gastronomia e promovendo o lugar seja proporcionalmente elevado quando comparado ao tamanho da população da cidade. Esta tendência também foi percebida na França por Duféal (2001), para quem a Internet passa a ser uma ferramenta das coletividades territoriais onde a valorização turística e dos produtos típicos se faz presente, como forma de se fazer conhecer pelo restante do país - e potencialmente pelo mundo - e de vencer o isolamento físico. Ao disponibilizar conteúdo online, elas aumentam sua visibilidade e as chances de atraírem visitantes e consumidores, bem como de realizarem negócios.

Vários municípios bem colocados no ranking dos números relativos dos domínios têm pequeno tamanho populacional e pouca expressividade econômica, tais como Campina do Monte Alegre-SP (em $15^{\circ}$ lugar, com pouco mais de cinco mil habitantes, mas com 1,48 domínio por 100 moradores), Águas de São Pedro-SP (o município de menor área do Brasil) e Chupinguaia (RO). Isto ocorre devido ao baixo número de moradores, sendo que qualquer flutuação fortuita para cima no número de domínios fará este tipo de município obter uma posição marcante nos números relativos. Para buscar minimizar essa falsa valorização de cidades muito 


\section{CARTOGRAMA 2}

Densidade de domínios de Internet 2006

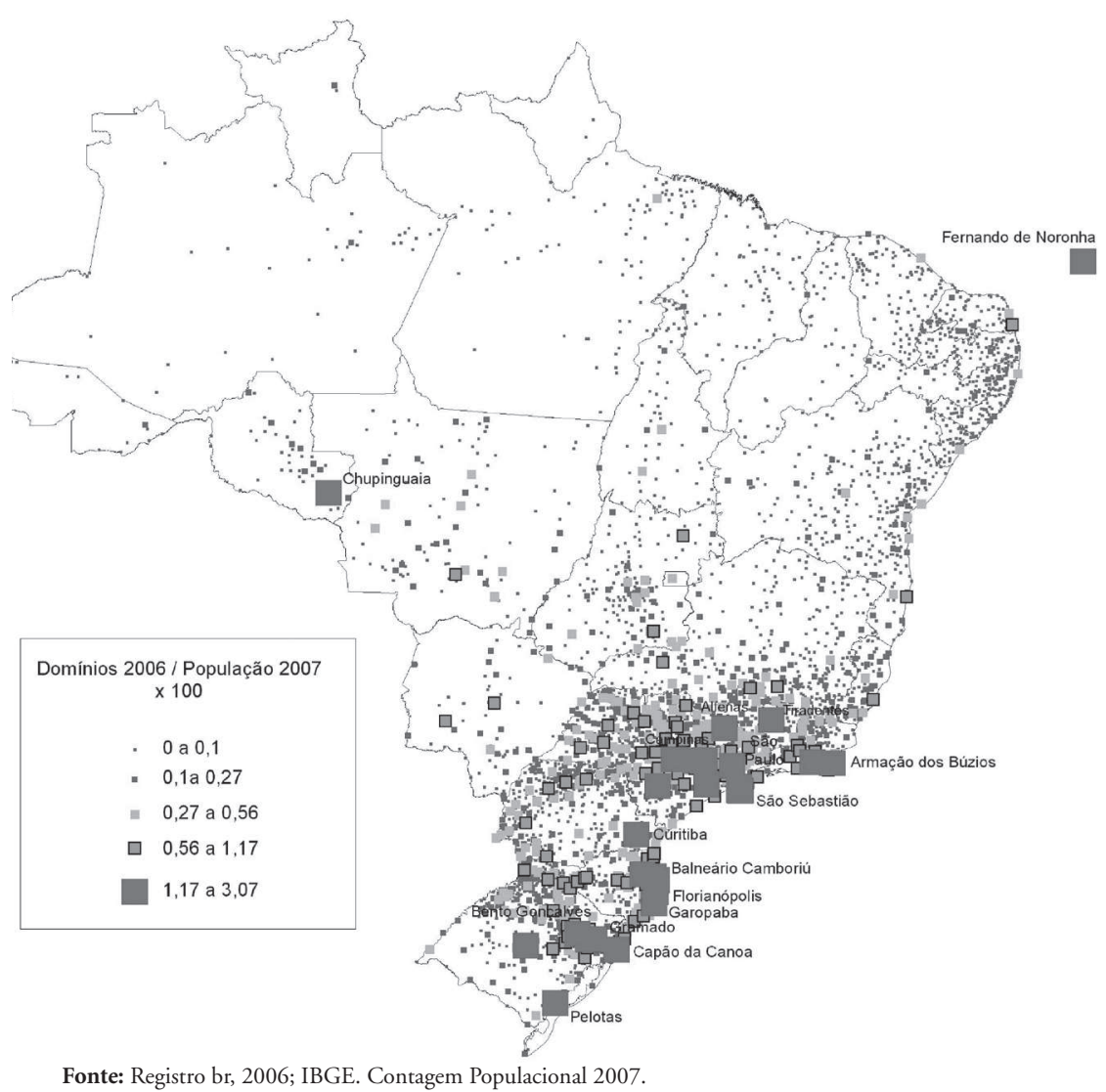

pequenas, foi realizado um corte a partir da aplicação do algoritmo de otimização de Jenks no ranking de população dos municípios, que identifica as quebras naturais no ordenamento do dado, agrupando os valores mais próximos entre si em uma mesma classe, ao mesmo tempo que maximiza a diferença entre elas. Para um total de seis classes de população, foi identificado o valor de 260.395 habitantes para selecionar os municípios de tamanho mais significativo, ${ }^{9}$ apresentados na Tabela 2.

9 De acordo com o histograma, a primeira classe, de 1.225 a 260.395 habitantes, possui 3.425 municípios. Sua exclusão eliminou, portanto, a imensa maioria dos municípios brasileiros. As classes seguintes são de 260.396 a 1.081 .041 habitantes, com 45 cidades; de 1.081.042 a 2.941.434 habitantes, com dez cidades; de 2.941 .435 a 11.667 .444 habitantes, com sete cidades; e, isoladamente, as ACPs do Rio de Janeiro, com 11.667 .445 habitantes, e São Paulo, com quase 20 milhões de pessoas. 
TABELA 2

Cidades com as maiores densidades de domínios por habitante Brasil - 2006

\begin{tabular}{llrrr|c}
\hline UF & \multicolumn{1}{c|}{ Cidade } & $\begin{array}{c}\text { Domínios } \\
\mathbf{2 0 0 6}\end{array}$ & $\begin{array}{c}\text { População } \\
\mathbf{2 0 0 7}\end{array}$ & $\begin{array}{c}\text { Domínios por } \\
\text { mil hab. }\end{array}$ \\
\hline RS & Pelotas & 8.514 & 534.285 & 15,94 \\
SC & Florianópolis & 12.831 & 806.132 & 15,92 \\
SP & São Paulo & 287.780 & 19.592 .238 & 14,69 \\
SC & Blumenau & 3.934 & 292.972 & 13,43 \\
PR & Curitiba & 39.038 & 3.001 .839 & 13,00 \\
RS & Porto Alegre & 32.715 & 2.941 .435 & 11,12 \\
SP & Ribeirão Preto & 7.369 & 722.182 & 10,20 \\
SP & Campinas & 24.985 & 2.460 .923 & 10,15 \\
RS & Caxias do Sul & 4.633 & 458.909 & 10,10 \\
SP & São José do Rio Preto & 4.792 & 491.468 & 9,75 \\
SP & Bauru & 3.346 & 347.601 & 9,63 \\
PR & Maringá & 4.420 & 507.416 & 8,71 \\
SP & Jundiaí & 5.234 & 618.628 & 8,46 \\
SP & Limeira & 2.229 & 272.734 & 8,17 \\
SP & Piracicaba & 2.910 & 358.108 & 8,13 \\
\hline
\end{tabular}

Fonte: Registro.br, 2006. IBGE, Contagem Populacional 2007.

A geografia dos domínios, quando ajustada pela população, fornece uma imagem consideravelmente diferente da hierarquia urbana em geral quando vista pelo tamanho demográfico das cidades. Apesar de São Paulo apresentar uma posição consistente com o fato de ser cabeça de rede, várias cidades médias ganham preeminência a expensas de Rio de Janeiro e Brasília, que estão no nível hierárquico funcional imediatamente abaixo (definidos em IBGE, 2008), embora a concentração nas Regiōes Sudeste e Sul permaneça e até se acentue quando comparada com o mapeamento absoluto ou com a distribuição de outros dados socioeconômicos sabidamente concentrados. Os Estados sulinos ganham significância, com suas capitais situando-se entre as seis maiores cidades com maior densidade de domínios, juntamente com São Paulo. Inversamente, cidades que possuem um número absoluto alto de domínios caem de maneira notável quando os valores são relativizados, tais como Rio de Janeiro, Belo Horizonte e Brasília. Nestes casos, pesa sua estrutura social interna muito de- 
sigual, em que a quantidade de domínios em suas periferias é menos significativo, diminuindo o número relativo de domínios no total da metrópole.

Esta situação indica que outros processos - além do mero peso demográfico ou posição na hierarquia das cidades - governam a presença de oferta de informações via Internet. Portanto, a seguir, verifica-se a relação entre as atividades econômicas em geral e a distribuição espacial dos domínios.

\section{Os domínios e as atividades econômicas}

O próprio caso da indústria do turismo, responsável pela maior penetração da Internet em vários municípios relativamente pequenos, mostra a relevância econômica do uso desta rede como instrumento de produção e agregação de valor.

Em uma análise bivariada comparando a quantidade de domínios nos municípios com a de empresas, a partir do cadastro de empresas do IBGE (2010), obteve-se um coeficiente de determinação $\left(\mathrm{R}^{2}\right)$ de 0,77 , indicando que a existência dos domínios está fortemente condicionada pela presença das atividades econômicas. Este valor é inclusive superior ao da mesma relação feita com a população da contagem 2007, que é de apenas 0,56 .

Ressalva-se que a estrutura de denominaçôes dos domínios de topo e o vínculo institucional a que eles se referiam inicialmente (“.com” para negócios, “.org” para entidades sem fins lucrativos, ".net" para administradores de infraestrutura de rede, etc.) acabaram tornando-se frouxos com o tempo, pois o uso corriqueiro dos domínios".com" fez com que ele se transformasse no padrão mais usual, independente de seu conteúdo. Todavia, a base de dados presentemente utilizada data de março de 2006, momento em que o Registro.br ainda requeria um CNPJ para o registro de domínios “.com.br". Isto significa que mais de $90 \%$ dos domínios aqui tratados $^{10}$ estão vinculados a uma empresa formalmente estabelecida, reforçando a validade da comparação dos domínios de Internet com as atividades econômicas.

Para avaliar o papel da dimensão econômica na oferta de informações na Internet, uma técnica útil é a criação de um índice que compara o quanto cada município sofre penetração da Internet quando comparado com as atividades econômicas formais. Para tanto, utilizou-se o método de Zook (2000), que confronta o número de

10 O conjunto dos domínios que não são ".com.br", como aqueles voltados a profissionais liberais, instituições ou para fins não comerciais, como os "org.br", "edu.br" etc., compõe menos de $10 \%$ do total. Individualmente sua participação é marginal, estando os domínios "net.br" na segunda posição, na ordem de 3\% (http://registro.br/ estatisticas.html). 
domínios e o total de empresas de cada localidade com a média nacional, de acordo com a fórmula do Índice de Especialização de Domínios (IED):

$$
I E D=\frac{D_{j} \div E_{j}}{D \div E}
$$

onde $D$ representa o número de domínios, $E$ corresponde ao número de empresas e $j$ refere-se às quantidades no município ou ACP.

Valores maiores do que 1 indicam que a cidade em questão possui uma maior penetração da Internet e uma maior intensidade da oferta de domínios quando comparados com a média nacional da relação, mostrando uma maior propensão do lugar à economia digital e uma possível maior especialização em transações online. Os valores inferiores a 1, abaixo da média nacional, por sua vez, indicam baixa produção de conteúdo econômico na rede, estando a economia local mais voltada para as atividades convencionais. ${ }^{11}$

A aplicação da fórmula ratifica, na comparação com as atividades econômicas em geral, a grande concentração da produção de conteúdo da Internet. Dos 3.490 municípios ou ACPs com domínios, somente 67 obtiveram um índice superior a 1 , e a mediana do conjunto é de apenas 0,13 . As desigualdades espaciais usuais no Brasil também se replicam. Tomando o caso das capitais estaduais como exemplo, todas as das Regióes Sul, Sudeste e Centro-Oeste, exceto Goiânia, possuem índices superiores a 1, às quais se soma Salvador. As demais capitais das Regiōes Nordeste e Norte têm índices variando de 0,98 (Belém) a 0,3 (Boa Vista). Destacam-se os casos de Fortaleza (IED de 0,78), que, com mais de dez mil domínios, não consegue se aproximar do próprio volume de empresas nela localizado, indicando um baixo uso da Internet enquanto ferramenta de geração de valor, e de Manaus (IED de 0,88), polo produtor de eletrônicos, cuja marcante falta de especialização de domínios é sintoma do modelo importador/montador de distrito industrial lá formado.

Entre os municípios com maior IED, apresentados na Tabela 3, chama a atenção o fato de municípios economicamente inexpressivos aparecerem bem colocados no ranking, como Chupinguaia (RO), Silva Jardim (RJ), São Félix do Tocantins (TO), Serra do Mel (RN) e também outros não ilustrados na tabela, como Guaraqueçaba (PR) na $31^{a}$ posição e Canhoba (SE), em $35^{\text {a }}$. Isto se deve, contudo, ao efeito dos pequenos números. Municípios de apenas 8 a pouco mais de 100 empresas podem,

11 Como este tipo de índice locacional pode acarretar uma sobrevalorização de áreas de economia pouco diversificada, realizou-se um teste utilizando a metodologia de Crocco et al. (2008), que busca superar esse problema criando um Índice de Concentração normalizado, combinando três indicadores. Contudo, no presente caso, seus resultados foram muito similares ao IED, o qual optou-se por manter. 
casualmente, ter um número de domínios acima do esperado em relação ao tamanho de suas economias locais em virtude da atuação de indivíduos ou entidades locais, sem que isso represente uma tendência mais geral. ${ }^{12}$

TABELA 3

As 30 maiores cidades pelo índice de especialização de domínios Brasil - 2006

\begin{tabular}{|c|c|c|c|c|c|}
\hline & UF & Cidade & Empresas & Domínios & IED \\
\hline 1 & RO & Chupinguaia & 106 & 125 & 5,76 \\
\hline 2 & $\mathrm{SP}$ & São Sebastião & 2.527 & 1.727 & 3,34 \\
\hline 3 & MG & Alfenas & 2.355 & 1.550 & 3,22 \\
\hline 4 & RJ & Silva Jardim & 256 & 164 & 3,13 \\
\hline 5 & RS & Pelotas & 15.921 & 8.514 & 2,61 \\
\hline 6 & PE & Fernando de Noronha & 182 & 86 & 2,31 \\
\hline 7 & SP & Santo Antônio do Pinhal & 218 & 94 & 2,11 \\
\hline 8 & SC & Garopaba & 716 & 307 & 2,10 \\
\hline 9 & SP & São Paulo & 690.029 & 287.780 & 2,04 \\
\hline 10 & SP & Caraguatatuba & 3.019 & 1.173 & 1,90 \\
\hline 11 & RJ & Arraial do Cabo & 572 & 216 & 1,85 \\
\hline 12 & SC & Florianópolis & 34.032 & 12.831 & 1,84 \\
\hline 13 & RJ & Rio de Janeiro & 245.125 & 87.229 & 1,74 \\
\hline 14 & PR & Curitiba & 113.226 & 39.038 & 1,69 \\
\hline 15 & MS & Bonito & 471 & 159 & 1,65 \\
\hline 16 & RJ & Armação dos Búzios & 1.418 & 461 & 1,59 \\
\hline 17 & $\mathrm{SP}$ & Ilhabela & 1.029 & 328 & 1,56 \\
\hline 18 & $\mathrm{SP}$ & Campinas & 82.113 & 24.985 & 1,49 \\
\hline 19 & $\mathrm{SP}$ & Holambra & 572 & 174 & 1,49 \\
\hline 20 & $\mathrm{SP}$ & Bauru & 11.548 & 3.346 & 1,42 \\
\hline 21 & TO & São Félix do Tocantins & 7 & 2 & 1,40 \\
\hline 22 & RN & Serra do Mel & 28 & 8 & 1,40 \\
\hline 23 & MS & Campo Grande & 18.399 & 5.209 & 1,38 \\
\hline 24 & RJ & Paraty & 843 & 233 & 1,35 \\
\hline 25 & $\mathrm{SP}$ & Jundiaí & 19.264 & 5.234 & 1,33 \\
\hline 26 & RS & Capão da Canoa & 2.810 & 762 & 1,33 \\
\hline 27 & RS & São João do Polesine & 122 & 33 & 1,32 \\
\hline 28 & RS & Porto Alegre & 121.333 & 32.715 & 1,32 \\
\hline 29 & $\mathrm{SP}$ & Limeira & 8.420 & 2.229 & 1,29 \\
\hline \multirow[t]{2}{*}{30} & $\mathrm{SP}$ & Peruíbe & 1.436 & 375 & 1,28 \\
\hline & & Total nacional & 4.420 .345 & 887.006 & 1 \\
\hline
\end{tabular}

Fonte: IBGE - Cadastro Central de Empresas, 2008; Registro.br, 2006.

12 No caso específico de Chupinguaia (RO) o município não possuía domínios em 2005, saltando para 125 em 2006, o que acarretou que sua posição fosse alçada para primeiro lugar. 
Da mesma maneira que no ajuste por população, também aqui se percebe o peso do setor turístico, já que diversos municípios com essa vocação aparecem novamente nesta listagem (Arraial do Cabo, Bonito, Búzios, Ilhabela, Paraty).

Quando se consideram todas as 30 cidades com maior índice de especialização, chama a atenção o fato de 11 delas localizarem-se no Estado de São Paulo, incluindo a capital e a metrópole de Campinas. A concentração de cidades com maior propensão ao uso econômico da Internet se dá no Estado que aglomera historicamente os setores industriais clássicos e, mais recentemente, os serviços avançados da economia informacional. Isto sugere que, mesmo sendo a Internet uma tecnologia capaz de transcender o espaço, quando vista pela ótica econômica, as relaçôes de proximidade e a necessidade das empresas que operam por meio da Internet de se localizarem nos núcleos mais dinâmicos da economia são fatores importantes, apoiando-se nas externalidades aí presentes. Como observado por Lasserre (2000), as empresas que optam por relacionarem-se com seus fornecedores e clientes via Internet, mesmo que parcialmente, precisam no mínimo de conceber, manter e atualizar constantemente a estrutura de seus sites, sem o que seriam rapidamente superadas por seus concorrentes. Isto implica, apenas para realizar e possuir uma interface na web, ter contatos frequentes com empresas e profissionais que prestem serviços de informática, sem contar com toda a logística já necessária para operação de seus negócios no mundo offline, como transporte de mercadorias, peças, insumos, componentes, criação de arcabouço jurídico de operação, manutenção de uma rede social de indivíduos que conheçam clientes, potenciais empregados, novos fornecedores, acesso ao crédito, ao mercado consumidor, entre outras facetas de operacionalização de negócios.

$\mathrm{O}$ ranking de cidades segundo o IED, entretanto, apresenta um quadro extremamente díspar, comparando diretamente pequenas cidades de economia pouco diversificada e grandes metrópoles. É necessário, então, da mesma forma que se buscou minimizar a flutuação dos pequenos números na comparação dos domínios com população, realizar um corte nos municípios com menos de 11.548 empresas com base no algoritmo de Jenks, ${ }^{13}$ como um proxy para as cidades de maiores relevância e complexidade econômica. O resultado encontra-se na Tabela 4, concentrando as cidades de maior peso econômico onde a relação domínios/empresas ultrapassa a média nacional.

13 O histograma de distribuição das empresas em seis classes compreende: de 7 a 11.547 empresas (3.446 municípios); de 11.548 a 44.746 empresas (31 cidades); de 44.747 a 113.225 empresas(sete cidades); de 113.226 a 245.124 empresas (três cidades); 245.125 empresas (somente Rio de Janeiro); e 690.029 empresas (apenas São Paulo). 
TABELA 4

Cidades com IED maior que 1, acima de 11.548 empresas Brasil - 2006

\begin{tabular}{rrlr|r|r}
\hline & UF & \multicolumn{1}{c|}{ Cidade } & Empresas & Domínios & \multicolumn{1}{c}{ IED } \\
\hline 1 & RS & Pelotas & 15.921 & 8.514 & 2,61 \\
2 & SP & São Paulo & 690.029 & 287.780 & 2,04 \\
3 & SC & Florianópolis & 34.032 & 12.831 & 1,84 \\
4 & RJ & Rio de Janeiro & 245.125 & 87.229 & 1,74 \\
5 & PR & Curitiba & 113.226 & 39.038 & 1,69 \\
6 & SP & Campinas & 82.113 & 24.985 & 1,49 \\
7 & SP & Bauru & 11.548 & 3.346 & 1,42 \\
8 & MS & Campo Grande & 18.399 & 5.209 & 1,38 \\
9 & SP & Jundiaí & 19.264 & 5.234 & 1,33 \\
10 & RS & Porto Alegre & 121.333 & 32.715 & 1,32 \\
11 & MG & Belo Horizonte & 132.449 & 34.110 & 1,26 \\
12 & PR & Maringá & 17.545 & 4.420 & 1,23 \\
13 & SC & Blumenau & 15.944 & 3.934 & 1,21 \\
14 & SP & São José dos Campos & 34.464 & 8.371 & 1,19 \\
15 & SP & Piracicaba & 12.223 & 2.910 & 1,16 \\
16 & SP & Santos & 41.881 & 9.580 & 1,12 \\
17 & SP & Sorocaba & 32.897 & 7.256 & 1,08 \\
18 & SP & Ribeirão Preto & 33.740 & 7.369 & 1,07 \\
19 & MT & Cuiabá & 19.766 & 4.286 & 1,06 \\
20 & BA & Salvador & 70.048 & 15.141 & 1,06 \\
21 & DF & Brasília & 81.112 & 17.441 & 1,05 \\
22 & ES & Vitória & 44.747 & 9.555 & 1,04 \\
23 & SC & Joinville & 26.570 & 5.522 & 1,02 \\
24 & SP & São José do Rio Preto & 23.380 & 4.792 & 1,00 \\
& & Total Nacional & $\mathbf{4 2 0 . 3 4 5}$ & $\mathbf{8 8 7 . 0 0 6}$ & $\mathbf{1}$ \\
\hline
\end{tabular}

Fonte: IBGE - Cadastro Central de Empresas, 2008; Registro.br, 2006.

Com essa seleção, a maior parte das cidades de especialização turística foi eliminada, isolando o efeito dessa atividade na composição dos domínios. Nota-se mesmo um aumento da representatividade do Estado de São Paulo e de suas cidades médias, bem como das principais metrópoles brasileiras, exceto Recife. Dessa maneira, é possível verificar que os negócios que operam com auxílio da Internet não anulam o espaço, pulverizando-se pelo país, mas têm um potencial relativo de reorganizar as escolhas e as regras nas quais operam. De um lado, reproduz-se a estrutura econômica concentrada que caracteriza o país; de outro, algumas cidades de porte médio parecem saber aproveitar as novas oportunidades geradas pela eco- 
nomia digital, tendo um desempenho acima do que se espera pela escala de suas economias, tais como Pelotas, Bauru e Maringá. Já a presença de Cuiabá e Campo Grande indica que os agronegócios podem ter uma influência positiva no que diz respeito à presença da Internet no campo dos negócios.

\section{Análise da evolução 2005-2006}

A comparação da distribuição dos domínios entre os dois anos que compõem a base de dados chama atenção pela semelhança, em que pese haver aumento significativo em seu número entre 2005 e 2006, de aproximadamente 22\%. Isto sugere a tendência do fenômeno espacial de se reproduzir no tempo, mantendo sua forma. Alguns números podem ser observados na Tabela 5, enquanto sua distribuição espacial encontra-se no Cartograma 3:

TABELA 5

Evolução dos domínios

Brasil - 2005-2006

\begin{tabular}{lcc}
\hline \multicolumn{1}{c|}{ Crescimento } & $\mathbf{N}^{\mathbf{0}}$ de cidades \\
\hline Positivo & 2.376 \\
Nulo & 670 \\
Negativo & 443 \\
Total (1) & $\mathbf{3 . 4 8 9}$ \\
\hline \multicolumn{2}{l}{ Cidades que deixaram de ter domínios } \\
em 2006 & 122 \\
Cidades que passaram a ter domínios & 441 \\
em 2006 & \\
\hline
\end{tabular}

Fonte: Registro.br, 2005, 2006

(1) Total das cidades com pelo menos um domínio em 2005 ou 2006.

O próprio comportamento insular da distribuição dos domínios, aglomerando-se em núcleos com espaços relativamente vazios entre eles - como indicado pelo índice de autocorrelação espacial - já parece indicar que sua evolução temporal segue a forma clássica apontada pela teoria da difusão de inovaçôes: a partir das localizaçôes iniciais de aceitação da inovação, sua disseminação se dá de maneira radial acompanhada pelo surgimento de aglomerações secundárias, enquanto os centros originais de seu surgimento continuam a se condensar em termos de um maior número de adotantes (HÄGERSTRAND, 1967, p. 133-134). 
Quando se comparam os Cartogramas 3 e 1, percebe-se que são exatamente os municípios de maior concentração de domínios que registram o maior crescimento positivo em seus números absolutos, corroborando a abordagem clássica. A adoção de novos domínios ocorre, sobretudo, onde eles já estão presentes, com os municípios que passaram a ter domínios somente em 2006 se espalhando pelo território. Estes últimos, embora possuam um padrão mais difuso, também aparecem em contiguidade com os núcleos já adotantes de maneira geral.

\section{CARTOGRAMA 3}

Evolução dos domínios - 2005-2006

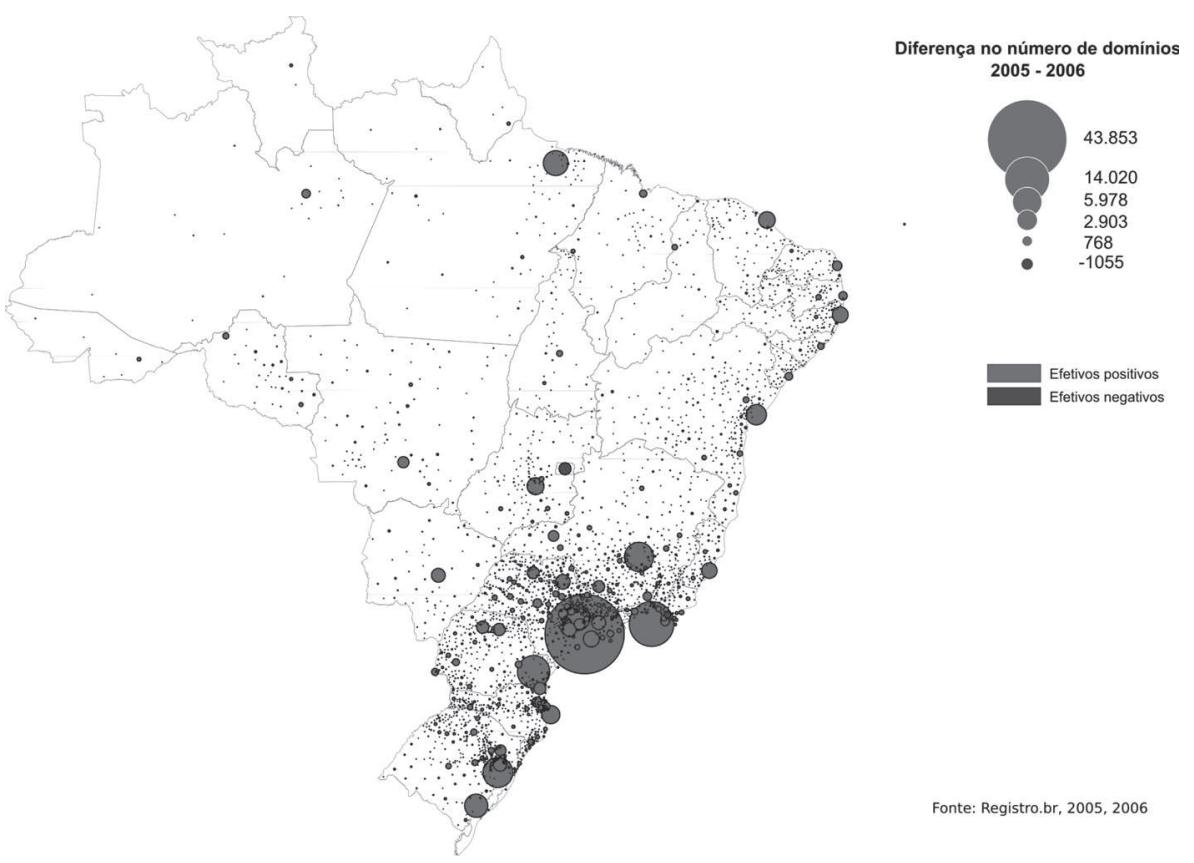

Os municípios que perderam domínios, por outro lado, tendem a se localizar em um padrão pulverizado, sendo Brasília a única exceção notável (com mais de 1.000 domínios a menos). Outras cidades que perderam domínios são Silva Jardim e São Fidélis, no Rio de Janeiro. O motivo dessa redução mais forte no número de domínios carece de investigação, sendo necessária a continuidade da série temporal para verificar se esta tendência se manteve nos anos posteriores. ${ }^{14}$

14 O caso de Silva Jardim (RJ) é bem característico de uma anomalia. Este município aparece em quinto lugar no IED, mesmo tendo perdido praticamente $65 \%$ de seus domínios entre 2005 e 2006 . Isto indica ou um erro na coleta dos dados, ou a presença de algum fator perturbador externo à economia local, como, por exemplo, um cybersquatter registrando vários domínios no mesmo endereço. 
O decréscimo de domínios, quando observado em termos relativos (Cartograma 4), indica uma maior propensão a perdê-los nas regiōes menos urbanizadas e mais distantes da core area de concentração das atividades econômicas. Os municípios que perderam todos os domínios localizam-se, principalmente, nas Regiōes Norte, Nordeste e Centro-Oeste.

\section{CARTOGRAMA 4}

Decréscimo relativo dos domínios - 2005-2006

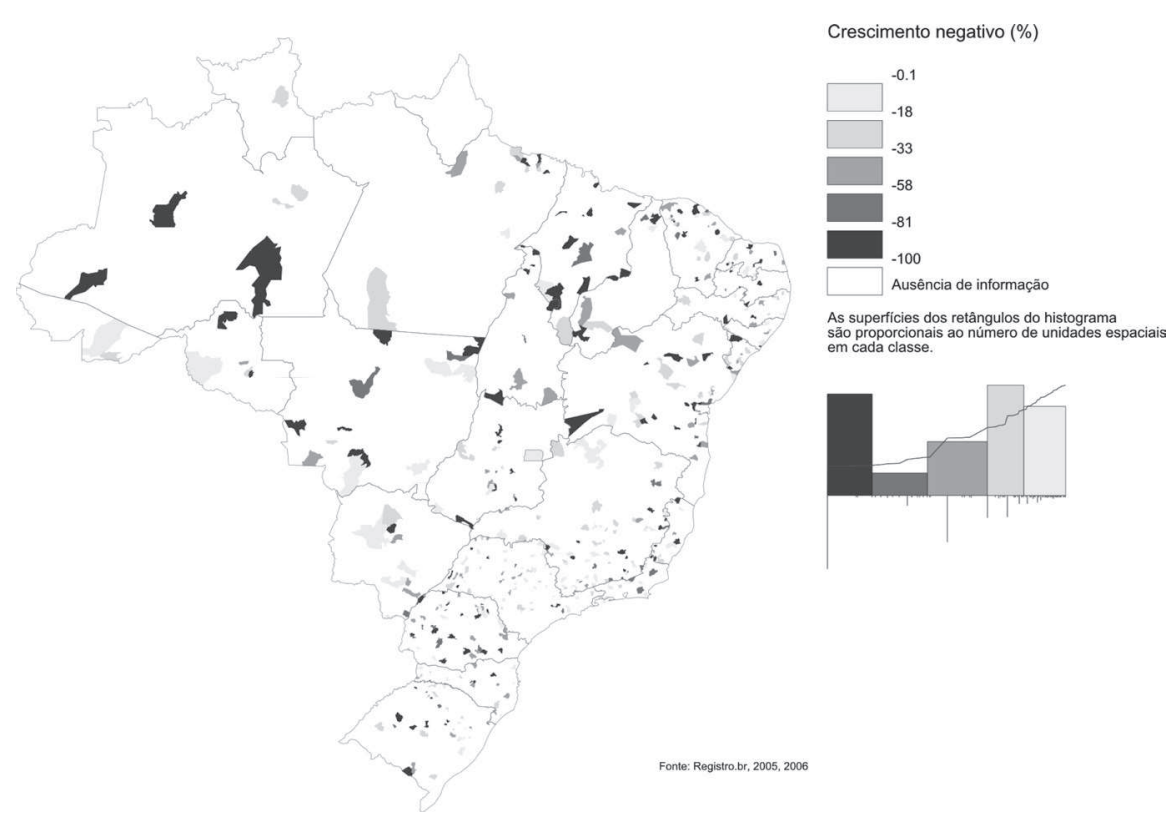

\section{Os domínios e a concentração espacial}

Como foi possível perceber neste artigo, a concentração é a tônica da presença da Internet no espaço concreto, quando vista sob a ótica da oferta de informaçóes, coincidindo com o esperado pelos aportes teóricos. Em seu nível mais básico, a Internet não existirá sem a infraestrutura que a sustenta e, mesmo onde estiver presente, necessitará de uma qualidade mínima desses serviços: rede elétrica estável e confiável; serviço de telefonia sem ruídos ou bons equipamentos para captação de ondas eletromagnéticas; provedor de acesso local; e um computador ou demais aparelhos corretamente configurados. Somente esses pré-requisitos básicos, juntamente com a renda necessária para pagá-los, já excluem parte significativa do país 
da possibilidade de acesso, quanto mais da de criar conteúdo e gerar valor a partir da Internet. Assim, os locais que já possuem a infraestrutura de qualidade e mais pessoas capacitadas, com conhecimento técnico, são justamente aqueles mais conectados, com a presença mais notável dos domínios.

O princípio da centralidade parece continuar válido para a presença de domínios de Internet. Se, por um lado, a hierarquia urbana não é seguida à risca - o que seria de estranhar, pois trata-se de uma tecnologia que aproxima espaços -, de outro, ela também não é completamente desbaratada, sendo válida em seus traços mais gerais.

Dessa maneira, grosso modo, quanto maior a centralidade de uma cidade, maior é sua chance de ter uma presença marcante no espaço de fluxos indicado pela existência de domínios. Há a tendência de as maiores metrópoles serem as porçôes do território mais competitivas e internacionalizadas, mas seguindo um caráter macrorregional: o Centro-sul tem uma presença significativamente mais marcante na produção de conteúdo online do que o Nordeste e o Norte, reforçando os padrões concentrados de diversos indicadores prévios à disseminação da Internet. Entretanto, entre os municípios de menor nível na hierarquia urbana, os balneários e locais turísticos parecem ter a capacidade de explorar mais eficientemente o espaço de fluxos, detendo mais domínios - pelo menos na dimensão da oferta de informações via Internet.

O comportamento insular da distribuição dos domínios é consistente com aquilo que Dupuy (2002) chama de "efeito de clube", isto é, quanto mais usuários estiverem conectados à rede, navegando e também criando conteúdo em determinado local, mais pessoas ainda se sentirão encorajadas a também fazê-lo, formando um processo de retroalimentação positiva. Embora qualquer um possa comunicarse teoricamente com qualquer dos outros milhôes de usuários e acessar sites onde quer que esteja no mundo, o que governa o comportamento online é a congregação de preferências e afinidades. Apesar de não ser totalmente incomum a existência de grupos dispersos, as relações mais fortes são as que dependem da proximidade, como as de amizade, parentesco, trabalho, que contribuem para reforçar o padrão desigual da Internet.

Em relação às atividades econômicas, uma das explicações para a formação de aglomerações de empresas, sugerida pela baixa presença de municípios com índice de especialização de domínios acima de 1 , é a disponibilidade de mão de obra qualificada em uma área. Embora as empresas que atuam na Internet muitas vezes necessitem de uma força de trabalho cujas habilidades são bem recentes, sem aglomerações preexistentes - por exemplo, webdesign, conhecimentos em redes sociais, 
em marketing online, programação em Flash e Java, etc. -, a concentração de renda, das instituições educacionais de prestígio, das oportunidades de formação profissional e mesmo da infraestrutura no Brasil faze com que esse tipo de trabalhador não esteja facilmente disponível em qualquer lugar, sendo mais provável encontrá-lo nos grandes centros urbanos. As qualificações profissionais já estabelecidas são também centrais para as empresas inovadoras e as metrópoles constituem um ambiente propício para a formação das competências necessárias ao trabalho, pois somente nelas existirão redes densas de trocas de informação e conhecimento.

Nesse sentido, o padrão locacional dos municípios com especialização em domínios parece ocorrer de forma avessa ao que se imaginou quando da emergência do comércio eletrônico, uma vez que se consideravam as possíveis mudanças na cadeia de valor e na logística em relação às empresas tradicionais. Estas mudanças não se revelaram tão impositivamente.

A partir do que as evidências indicaram, na esfera dos negócios o caráter revolucionário da Internet dá lugar a processos incrementais, em que as mudanças vão se fazendo de forma lenta. As novas firmas de comércio eletrônico ou outra operação online que venham a iniciar sua atuação no mercado têm maior probabilidade de fazê-lo nos locais onde as redes de relações entre empresas já estejam estabelecidas.

Assim, os resultados observados e a forma espacial da distribuição dos domínios, aglomerando-se sobretudo nas metrópoles e em particular em São Paulo, são consistentes com a descrição da abordagem institucionalista - o trabalho das empresas online integra-se profundamente com o ambiente econômico, produzindo competências específicas do lugar.

Mergulhar no seio das relações interempresariais das regiões e discernir as mediações institucionais que lá têm lugar foge do escopo do presente trabalho. Embora não seja possível descrever acuradamente como se dá essa construção do ímpeto para a aglomeraçãa, pode-se perceber a inadequação da visão de Townsend (2001) para o caso brasileiro. Em que pese a coerência metodológica de seu estudo, este autor parece obter conclusões generalizantes a partir da extrapolação do caso americano, economia muito mais diversificada e pujante do que a maioria esmagadora dos países, havendo muito mais espaço para o surgimento de pontos secundários de suporte à economia informacional. Se nos EUA as cidades globais não exercem centralização dominante sobre os nós de atividades de Internet, o Brasil apresenta-se extremamente centralizado em termos de atividades informacionais em sua própria "cidade global", ou São Paulo. Apesar de regiões menores e especializadas descritas por Townsend não estarem totalmente ausentes no Brasil, a aglomeração maciça 
dos domínios e das cidades com alto índice de especialização parece apontar mais para a perspectiva institucionalista, sendo reflexo da maneira como as atividades econômicas em geral estão organizadas.

Além disso, a questão da logística também tem importante papel em explicar o porquê da aglomeração nos grandes centros urbanos, já que neles se localizam as redes desta atividade de maneira mais sólida, bem como a força de trabalho mais qualificada.

As metrópoles constituem o ambiente que, no Brasil, detém as maiores chances de possuir os pontos de apoio logísticos, os recursos imateriais e o quadro institucional descritos anteriormente. Porém, o mecanismo de retroalimentação positiva, conforme descrito por Arthur (1990), também pode gerar concentraçôes em outros centros urbanos, a partir de alguma vantagem inicial, como um programa dos governos locais de atração ou incubação de empresas, ou um grupo de empreendedores que invista localmente. A partir de um núcleo inicial de poucas empresas, as economias externas por elas geradas irão ser atrativas para novas empresas que venham a surgir. As localidades que nestes estágios iniciais venham a atrair mais firmas - às vezes por razões fortuitas, como a presença de amenidades - tornam-se cada vez mais uma opção preferencial para iniciantes. Com a intensificação dos ganhos gerados pela aglomeração de companhias, estes locais irão trazer para si ainda mais atividades e, assim, a concentração torna-se um processo que se auto-reforça. As cidades médias que se caracterizam pela presença de um alto índice de especialização de domínios podem ser explicadas por esse mecanismo.

Em relação à evolução do número de domínios nos dois anos observados, notou-se que sua forma espacial é consistente com a da abordagem clássica de Hägerstrand. $\mathrm{O}$ fato de que a difusão espacial de uma tecnologia nova e cada vez mais popular possa ser descrita por uma teoria criada há mais de 50 anos vem reforçar a ideia de que as estruturas da Internet, vistas sob a ótica geográfica, não representam uma revolução no que tange à geografia econômica prévia. Elas antes refletem os processos econômicos do que os forçam a uma alteração de padrão. A adoção desta nova tecnologia, em sua dimensão da oferta de informações, ocorre sobretudo nas áreas onde ela já está presente de maneira mais maciça, reforçando a concentração dos recursos materiais e imateriais e contribuindo para falsear a ideia de anulação do espaço.

Mesmo em ritmo bem mais lento e em quantidades menores, a difusão dos domínios também se faz em áreas não metropolitanas e em porçôes dos territórios de baixa concentração, o que leva a questionar parcialmente a noção de exclusão 
ou divisão digital - que evoca um abismo intransponível entre os que têm e os que não têm acesso às tecnologias. De acordo com a teoria de difusão de inovações, é da natureza mesma do processo inovativo que alguns lugares e pessoas tenham acesso a uma nova tecnologia primeiro - nomeadamente os mais ricos e as regióes mais densas -, enquanto outros só terão acesso bem mais tarde.

Entretanto, conforme argumentado por Dupuy (2007), falar em exclusão digital não é mero "abuso de linguagem", porque, mesmo com o processo contínuo de difusão ao longo do tempo, as novas tecnologias de informação e comunicação não possuem estabilidade tecnológica de longa duração. As mudanças e inovaçōes constantes garantem que a fratura esteja sempre presente, já que aqueles com maior capacidade de adoção irão sempre se beneficiar primeiro delas. E no caso brasileiro, a possibilidade de oferta de conteúdo esbarra nas características socioeconômicas do território - como as diferenças dos níveis educacionais e de renda - e na presença da infraestrutura que fornece a base material para o funcionamento da Internet, como demonstrado em Motta (2011).

\section{Referências bibliográficas}

ABBATE, J. Inventing the Internet. Cambridge, MA: The MIT Press, 2000.

ADAMS, P. Cyberspace and virtual places. The Geographical Review, v. 87, n. 2, p. 155171, 1997.

AMIN, A. An institutionalist perspective on regional economic development. International Journal of Urban and Regional Research, v. 23, n. 2, p. 365-378, 2002.

ANDERSON, C.; WOLFF, M. The web is dead. Long live the internet. Wired Magazine, 18.09, September, 2010. Disponível em <http://www.wired.com/magazine/2010/08/ff_webrip/all/1>. Acesso em: 03 fev. 2012.

ARTHUR, B. Positive feedbacks in the economy. Scientific American, n. 262, p.92-99, 1990.

BATTY, M. Virtual geography. Futures, v 29, n. 4-5, p. 337-352, 1997.

BROWN, L. Innovation diffusion. A new perspective. New York: Methuen, 1981.

CASTELLO BRANCO, M. L. Áreas de concentração de população. In: II ENCONTRO NACIONAL DE PRODUTORES E USUÁRIOS DE INFORMAÇŌES SOCIAIS, ECONÔMICAS E TERRITORIAIS. Rio de Janeiro, 2006.

CASTELLS, M. A sociedade em rede. São Paulo: Paz e Terra, 1999. 
CROCCO, M. A. et al. Metodologia de identificação de aglomeraçōes produtivas locais. Nova Economia, v. 16, n. 2, p. 211-241, 2008.

CURRAH, A. Behind the web store: the organisational and spatial evolution of multichannel retailing in Toronto. Environment and Planning A, v. 34, n. 8, p. 1411-1441, 2002.

CARVALHO, M. et al. O controle do namespace no ciberespaço. 2004. Disponível em: <http:// www.socid.org.br/textos.htm>. Acesso em: 26 ago. 2011.

DUFÉAL, M. Internet, marqueur des territoires? Le cas de la diffusion web dans l'Arc Mediterranéen français. In: V RENCONTRES DE THÉO QUANT. Besançon, 22-23 février 2001.

. Mesure de la diffusion spatiale des sites web dans les régions mediterranéennes françaises. In: GUICHARD, E. (Ed.). Mesures de l'Internet. Paris: Les Canadiens en Europe/ INRIA, 2004.

DUPUY, G. La fracture numérique. Paris: Ellipses, 2007. Internet: géographie d'un réseau. Paris: Ellipses, 2002.

GRAHAM, M. Time machines and virtual portals: the spatialities of the digital divide. Progress in Development Studies, v. 11, n. 3, p. 211-227, 2011.

HÄGERSTRAND, T. Innovation diffusion as a spatial process. Chicago: The University of Chicago Press, 1967.

IBGE. Estatísticas do Cadastro Geral de Empresas 2008. Rio de Janeiro: IBGE, 2010. Regiōes de influência das cidades. Rio de Janeiro: IBGE, 2008.

LASSERRE, F. Internet: La fin de la géographie? Cybergeo: European Journal of Geography, n. 141, 2000. Disponível em: <http://cybergeo.revues.org/4467>. Acesso em: 25 ago. 2011.

LEAMER, E.; STORPER, M. The economic geography of the internet age. Journal of Internation Business Studies, v. 32, n. 4, p. 641-665, 2001.

MASKELL, P. Growth and the territorial configuration of economic activity. In: THE DRUID SUMMER CONFERENCE, 2001. Disponível em: <http://www.druid.dk/conferences/nw/paper1/maskell.pdf>. Acesso em: 25 ago. 2011.

MOTTA, M. Geografia da internet no Brasil: redes técnicas e espaço. Tese (Doutorado). Rio de Janeiro: UFRJ/PPGG, 2011.

NAUGHTON, J. A brief history of the future. Woodstock, NY: The Overlook Press, 2000.

OLIVEIRA, E. et al. A difusão vista através de um prisma - A geografia. Revista Brasileira de Geografia, v. 40, n. 1, p. 83-110, 1978. 
PUMAIN, D.; SAINT-JULIEN, T. L'analyse spatiale 1. Localisations dans l'espace. Paris: Armand Colin/Masson, 1997.

STERNBERG, R.; KRYMALOWSKI, M. Internet domains and the innovativeness of cities/regions - Evidence from Germany and Munich. European Planning Studies, v. 10, n. 2, p. 251-273, 2002.

STORPER, M. The regional world. New York: Guilford, 1997.

TAKEYAMA, M. Geographical conceptualizations of cyberplaces. Geojournal, v. 53, n. 4, p. 419-426, 2001.

THORNTON, M.; MARCHE, S. Sorting through the dot bomb rubble: how did the high-profile e-tailers fail? International Journal of Information Management, v. 23, n. 2, p. 121-138, 2003.

TOWNSEND, A. The internet and the rise of the new networked cities, 1969-1999. Environment and Planning B, v. 28, n. 1, p. 39-58, 2001.

VERISIGN. O dossiê sobre a indústria de domínios na internet, v. 7, n. 2, 2010. Disponível em: <https://www.verisign.com.br/domain-name-services/domain-information-center/ industry-brief/index.html>. Acesso em: 26 ago. 2011.

WRIGLEY, N.; CURRAH, A. Globalizing retail and the 'new e-economy': the organizational challenge in the e-commerce for retail TNCs. Geoforum, v. 37, n. 3, p. 340-351, 2006.

ZOOK, M. The geography of internet industry. Malden, MA: Blackwell, 2005.

. Old hierarchies or new networks of centrality? The global geography of internet content market. American Behavioral Scientist, v. 44, n. 10, p. 1679-1696, 2001.

. The web of production: the economic geography of internet content production in the United States. Evironment and Planning A, v. 32, n. 3, p. 411-426, 2000.

ENDEREÇO PARA CORRESPONDENCIA

Marcelo Paiva da Motta - marcelo.motta@ibge.gov.br Coordenação de Geografia, IBGE Avenida República do Chile, 500, $15^{\circ}$ andar 20031-170 - Rio de Janeiro (RJ) 